\title{
Sustainable development of water resources in the Brahmaputra and Barak River system of northeast India
}

\author{
N. Sharma \\ DHI(I), Assam, India
}

\begin{abstract}
The Brahmaputra and Barak River Basins are, along with the Ganges River, major parts of the Meghna Basin. The Brahmaputra and Barak River system covers more than half of the area of the north eastern region of India and has particular opportunities for sustainable development, as well as distinct challenges. Located in the high rainfall zone of India, the Brahmaputra and Barak Basins feature a water resources potential much above the requirement, unlike the rest of India, where water shortages are alarmingly escalating. A major ordeal is the frequent floods and the strong bank erosion, affecting the entire socio-economic scenario of the region, and also disturbing the ecological balance, in addition to the loss of life and properties. Efforts have been made (and are in progress) to deal with these problems, but the scale of the challenge is overwhelming.

This paper describes approaches to reducing the menace of flood and bank erosion through proper planning, community participation, and application of contemporary technologies, for identification of needs and opportunities, and for understanding the governing cause-effect relationships and the related management options. Hereby, the basis will be extended for timely and appropriate decisions on responsive as well as pro-active development, in support of the region's socio-economic prosperity and environmental health in general, and improved disaster resilience in particular.

Keywords: Brahmaputra, Barak, disaster resilience, sustainability, FREMAA, flash floods, wind-borne sand, NDMA, climate change, community participation.
\end{abstract}




\section{Introduction}

Sustainable development in the Brahmaputra and Barak river basins is visibly affected by widespread and significant exposures to floods and bank erosion, with additional potential future climate-related challenges, including drought.

The present paper compiles some information and observations about these concerns and related response and adaptation measures. The paper builds comprehensively on proceedings of the Institutional Strengthening Component of the ongoing Assam Integrated Flood \& River Bank Erosion Management Programme, implemented by Flood \& River Erosion Risk Management Authority of Assam (FREMAA).

\section{The Brahmaputra and the Barak River system}

The Brahmaputra originates in the Himalayas. It enters India in Arunachal Pradesh, from where it flows through Assam and further into Bangladesh (where it is known as Jamuna). The Indian part of the Brahmaputra Basin has an area of $195,000 \mathrm{~km}^{2}$. The state capital of Assam, Guwahati, is located on its left (southern) bank. The river joins the Padma (the major distributary of the Ganges) before discharging into the Bay of Bengal via the Meghna Estuary in Bangladesh. The total area of the system is 1.7 million $\mathrm{km}^{2}$.

The Barak River origins in Manipur, from where it flows into Mizoram and further to Assam, from where it flows into Bangladesh as a tributary to the Meghna River System. The Indian part of the Barak Basin has an area of $41,200 \mathrm{~km}^{2}$.

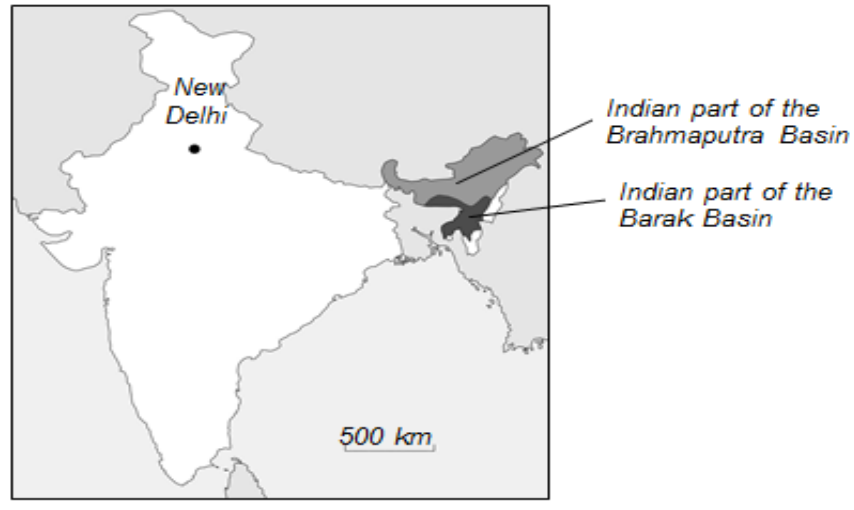

Figure 1: Location map.

Both the river basins of north-east region of India are located in one of the heaviest rainfall region of the world. The average annual rainfall over the Brahmaputra catchment is about $230 \mathrm{~cm}$. and that of the Barak is more than $300 \mathrm{~cm}$. As the major portion of these two river basins are lying in the hilly terrain, the tributaries of these two river system flow rapidly in steep slopes and 
consequently bring heavy flash floods. Another predominant factor of flooding is the spilling of rivers over their banks, drainage congestion and tendency to change its courses in various channels created due to the braided nature. In addition to the flood problem, the problem of bank erosion in the Brahmaputra River has become serious in the recent years. The flood accentuated by erosion and silting of river bed is resulting in reduction of the carrying capacity of the rivers.

\section{Disaster risk management agenda}

Disaster Management Authority in India has a very good framework at various levels with appropriate systems. These are mainly institutional mechanism, disaster mitigation and prevention processes, legal and policy framework, preparedness and response, A network of emergency operation centres, early warning systems, human resource development and capacity building, research and knowledge management, etc.

\subsection{Exposure}

Most of the Indian parts of the basins are alluvial flood plains, with large areas exposed to floods and severe bank erosion. There are two kinds of floods: mainstream seasonal floods, caused by snowmelt in the Himalayas and southwest monsoon rains; and flash floods on the tributaries (with risks of land-slides), caused by local rainfall. The former can be predicted with a fair accuracy and a reasonable lead time, while the latter are more difficult to predict, and with a short lead time only. Urban floods occur regularly, also caused by local rainfall, and exacerbated by inadequate drainage capacity. Parts of the otherwise fertile agricultural lands are affected by deposits of wind-borne sand from dry river beds.

Management of floods and erosion are therefore necessary not only because it impose curse on the society, but also the optional exploitation of land and its control is of vital importance for bringing in prosperity to the society.

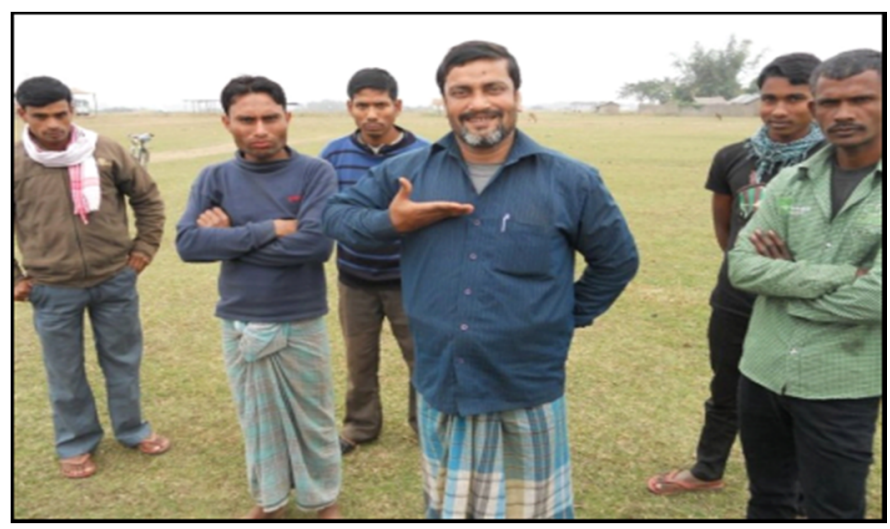

Figure 2: Showing the typical seasonal flood height. 


\subsection{Climate change implications}

Climate change particularly the variations in temperature and precipitation are the major factors that affect the disaster risk exposure - and perhaps significantly so. Climate change has several immediate implications in these areas:

- Even minor changes in the flood pattern can reduce the validity of local knowledge and traditional response (for example if the flood wave rises faster than hitherto experienced).

- Cultivation will be affected by the expected increased temperatures and rainfall, so that traditional crop varieties and well-proven practices may no longer be optimal. There is a scope for paying attention to the needs of adjustments (which could have benefits beyond climate change preparedness).

- Increased occurrence of erratic weather may include incidents of drought, for which the societies and production systems are under-prepared, since this is not a major concern today.

\subsection{Institutional arrangements}

Disaster management bodies exist at the following levels of administration:

- The National Committee on Disaster Management (NCDM) and the National Disaster Management Authority (NDMA), both under the Government of India

- State-level disaster management authorities

- District-level disaster management authorities (DDMAs) [1]

- Village-level disaster management committees (VDMCs) [2,3]

The national and state-level bodies prepare policies, plans, manuals and guidelines, and provide services in support of disaster resilience and recovery. The DDMAs prepare district disaster management plans; provide support to their implementation; conduct evacuation drills; and relay information (and experience) between the village level and the state level.

\section{Approach to sustainable development}

Sustainable development is no longer a mere scientific jargon, rather it is a practical management alternatives. In India, there are numerous initiatives taken to evolve action plan for sustainable development both at macro as well as micro level using latest innovations of science and technology and vast stock of traditional knowledge available in the country.

\subsection{Structural and non-structural measures}

Structural measures are indispensable [4]. Apart from dykes and bank protection they may include raised platforms (for people and/or livestock) and safe shelters where warranted. This may include new facilities and flood proofing of existing 
facilities such as schools, along with improved access to safe Water and sanitation during emergencies.

Bank erosion is a phenomenon which has been occurring along the Brahmaputra River since time immemorial, fig. 3, but after the construction of embankments in the 1950s (aftermath of the Assam 1950 earthquake) it has become much more threatening, because embankments might be eroded away during the monsoon causing flooding and serious damage. This is aggravated by the increasing population density and increasing number of assets behind the embankment. Timely warnings that serious bank erosion might occur in the near future are hence indispensable for proper management of embankments.

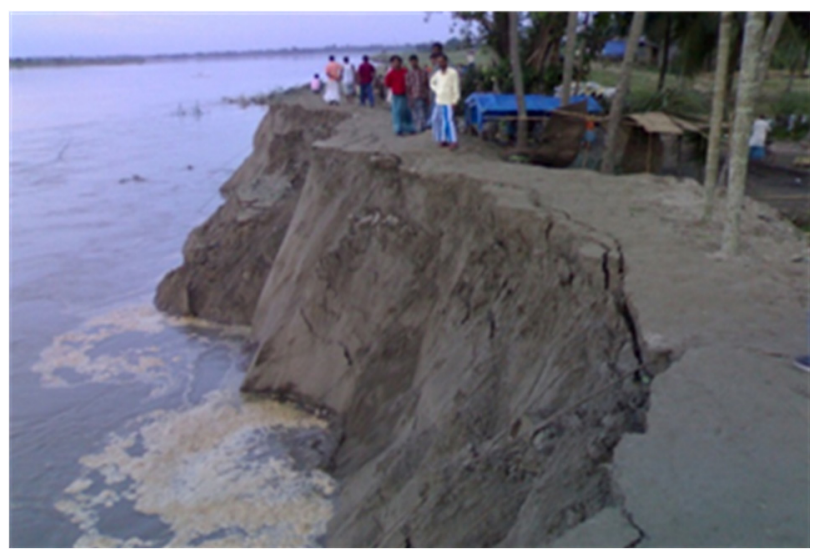

Figure 3: A scene of bank erosion in River Brahmaputra.

Bank erosion along braided rivers is not easy to predict, in particular not over longer periods of say five years. Bank erosion might occur at one location at a certain time, but a few years later the bank erosion might have vanished and attacks the river at another location. This implies that when bank protection works have been constructed after a few years, bank erosion might move to another location leaving the works and the investment lying idle for possibly quite substantial time. Hence a good prediction of locations wherein the near future bank erosion will occur and where it will vanish after a few years are hence indispensable for proper river management. Possible measures, which can be taken when it is predicted that serious bank erosion will occur along a certain reach over the coming years, are:

- Construction of bank protection works (figs. 4-9);

- Permanent or recurrent river training measures like closure of aggressive channels or dredging of pilot channels to divert the flow away from the bank under attack;

- Construction of retired embankments or the construction of a second line of embankments;

- Shifting of important infrastructure (roads, railroads, irrigation canals, bridges, transmission lines for electricity, etc.); 
- Relocation of the population at risk, including the dismantling of their houses to save building material from being eroded into the river;

- Relocation of other important buildings like schools, shopping areas, community centers etc.

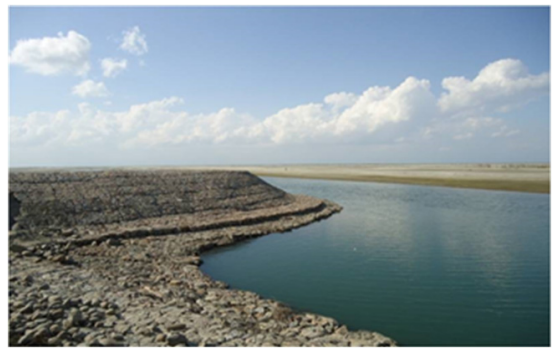

Figure 4: Boulder spur for deflection of flow.

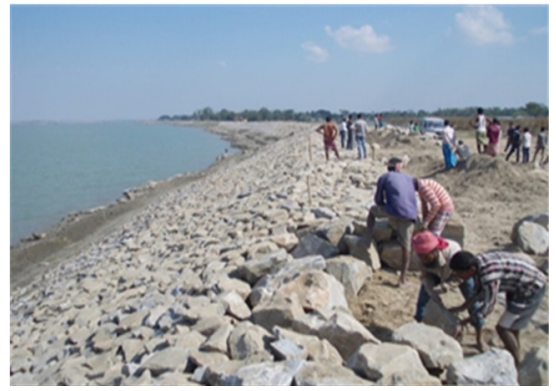

Figure 6: Use of boulder in bank revetment.

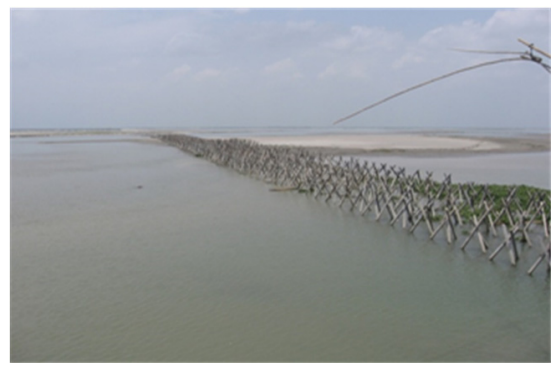

Figure 8: RCC porcupine for erosion protection.

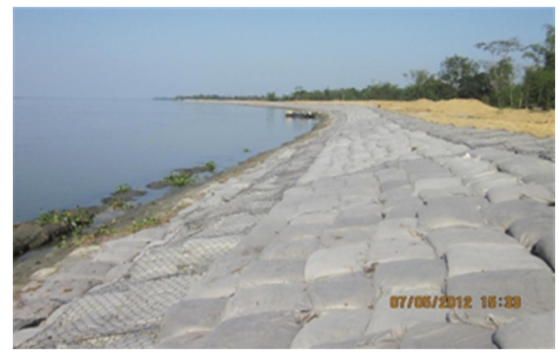

Figure 5: Geo synthetic bags in bank revetment.

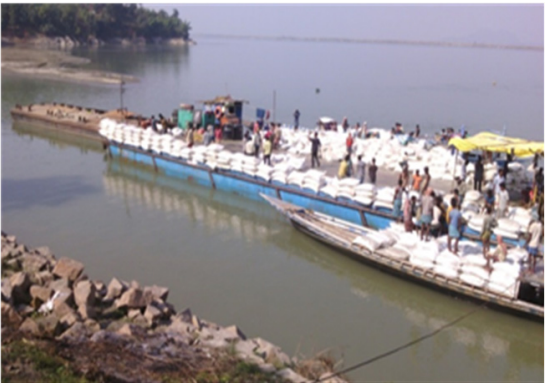

Figure 7: Dumping of geo bags near bank.

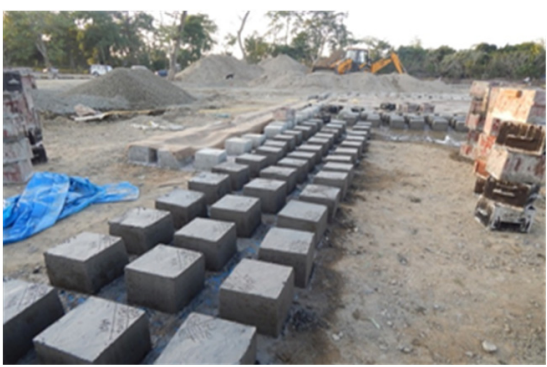

Figure 9: PCC blocks for bank revetment. 
Measures to maintain reliable communication (and electricity supplies) during floods are required for appropriate response and mitigation. Availability of small vessels (traditional country boats) can be critical during extreme floods. Stockpiling of food, medicine, livestock fodder and seeds will improve the resilience. Many drains are in need of repairs and/or capacity upgrading and/or orderly routine maintenance.

The existing flood early warning system [5] in the Brahmaputra main stem is limited to the information on the rise in water levels at different gauging stations installed in the entire stretch of the river but for the effective people oriented flood warning system is under the development stage which will provide rainfall and flood level forecast based on real time information, issue right warning to the right people and instruction to take proactive and appropriate measures to save lives and properties.

Livelihoods consolidation and development may include improved rice species (with higher yields and shorter cultivation periods); improved vegetables and perennial crops species; improved cultivation practices (with appropriate use of fertilizer and pesticides); and improved livestock breeds.

Soil management (using compost) can be introduced on a pilot basis where appropriate. Bag cultivation may be considered for small-scale cultivation in places with poor soils; this would be a low-risk and inexpensive experiment.

Also handicrafts and home industries may be promoted.

Japan Fund for Poverty Reduction (JFPR), working with NGOs, has recently supported small-scale livelihoods development in pilot areas in Assam, including equipment for silk spinning and weaving (along with support to improved cultivation).

A value chain perspective may be helpful in this connection, considering the value and livelihoods generated at all the steps from production of inputs to the eventual delivery of final products to the end consumer, assuming that improvements at one stage (for example marketing) can generate benefits at preceding and/or subsequent stages.

Production of fodder for livestock would be one activity to consider in this connection. Fodder for livestock is a major concern during floods. Fodder may be secured by local production and storage and/or safe external supplies. Also chicken fodder (based on soy beans) may be produced locally.

Extension services to cultivation and livestock breeding can introduce improved technology, seeds and breeds, and guide a timely and appropriate response to pests and diseases, reducing the risks of the producers. Agricultural experiment stations can play an important role in this connection, particularly if they operate local test facilities with actual, specific weather and soil conditions. These will know about new rice varieties, and may conduct local meteorological observations (of rain and sunlight radiation) that can be expanded by correlation to nearby long-term records, and which will assist in identification of new cultivation opportunities.

Vocational training has been suggested as a socio-economic development priority in places where many people earn their living outside the household and 
also elsewhere, such training is a safe strategy that can serve as a catalyst for the synergies between livelihoods and disaster resilience.

\subsection{Community participation $[6,7]$}

The village disaster management committees (VDMCs) were initiated in disasterprone villages around a decade ago, but remain in a state of consolidation. They relay information between the household level and the higher levels of administration. The VDMCs prepare disaster risk maps, fig. 10 and disaster management plans, and operate village-level disaster management teams that assist with evacuation, search and rescue, and first aid during disasters.

Among the important tasks of the VDMCs is to link the early warning services with operational, community-based emergency response preparedness, as it is presently being piloted under the Assam Integrated Flood \& River Bank Erosion Management Programme [8]. This will include different levels of alert, awareness of appropriate response at household level and contingency plans for evacuation. Community participation to Flood Risk Assessment.

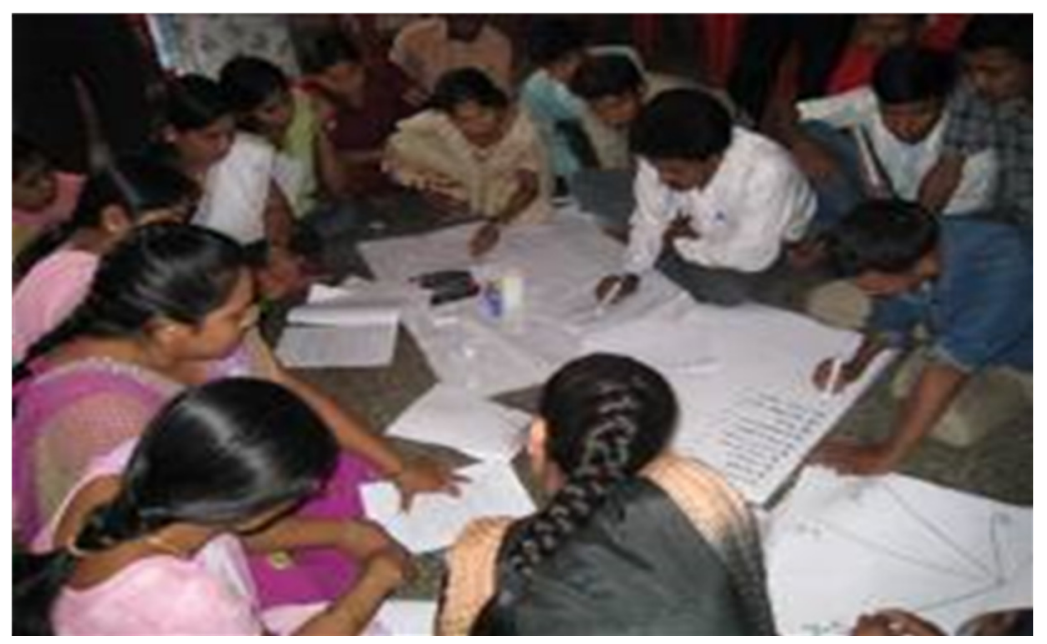

Figure 10: Participants are in risk mapping exercise.

The following proven basic initiatives are required for sustainability

- Involvement of the NDMA, SDMA and DDMA in various disaster management activities.

- $\quad$ Capacity building of the VDMC members.

- Village DM Volunteers elected under any project should be recognized by the Govt. level Disaster Management Authority.

- Initiative to link VDMCs in the process of preparing Community Development Plan.

- Initiative to link up VDMCs with local micro-finance organization. 


\subsection{Information flows and knowledge-sharing}

Smooth information flows and knowledge-sharing are important [9], within and between the management levels. Knowledge, in this connection, includes data, observations and experience covering exposures, vulnerabilities and preparedness; and understanding of cause-effect relationships and management options.

Information flows, fig. 11, follow a hub-and-spoke pattern, with ' $h u b s$ ' undertaking data compilation and relay at the village, district and state level, respectively. Knowledge about exposures provides an indispensable part of the basis for strategic adaptation, including feasibility assessment and structural design, as well as the operational preparedness. Some of the information about exposures is generated locally: Rainfall, flow rates and inundation, including 'normal' conditions and historical frequencies of occurrence (or 'risks'). Other important information is available from the state level and from global, satellitebased monitoring: DEM data, rainfall, inundation, and - not least - the occurrence and movement of tropical depressions (including cyclones).

Knowledge about vulnerabilities must cover households; schools and clinics; agriculture; other production systems; infrastructure (including connectivity and access) (roads, dikes, river banks, embankments, canals, reservoirs, power supply networks, telecommunication); and habitats and ecosystems. Much (but not all) information flows

Much (but not all) information flows about vulnerability goes mainly from the household and village level to the district and state level, with lateral knowledgesharing at each level. Information about preparedness and response options proceeds as a two-way process (see the figure below). Some of this knowledge serves important social, economic and environmental purposes that reach beyond disaster risk preparedness

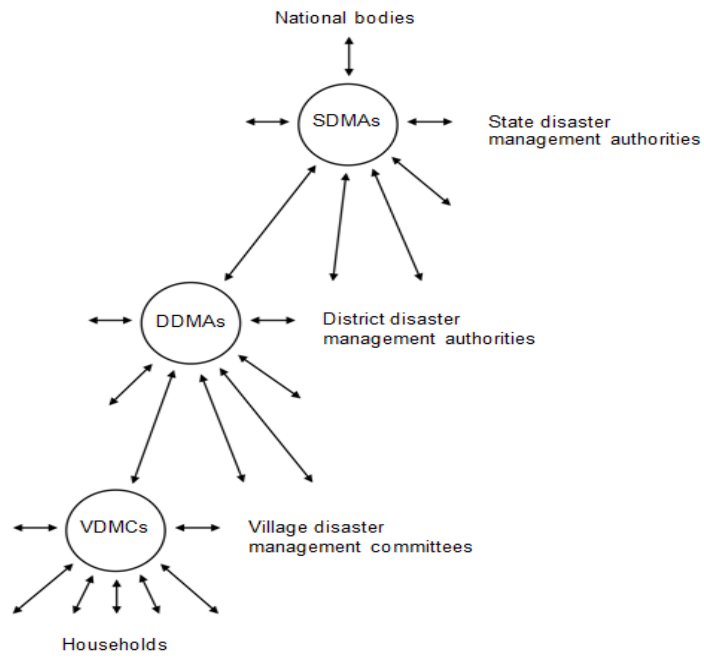

Figure 11: Information flows. 


\section{Discussion}

Findings may be summarized as follows:

- While each village has its own individual context and agenda, which must be duly observed, there is a clear scope for knowledge-sharing and replication of good practices among different villages.

- Disaster management requires multi-disciplinary and pro-active approach [10]. Besides various measures for putting in place by institutional and policy framework for disaster prevention, mitigation and preparedness initiatives need to be taken by the Central and State Governments, the community, civil society organizations and also media in achieving a sustainable solution.

- Disaster resilience and livelihoods are interdependent. Progress in one domain will inevitably add value to the other, while a deficit in one domain will inevitably impede progress in the other. A holistic approach is warranted.

- Developments towards improved water (and energy) efficiencies are among the several safe 'no-regrets' (or 'multiple benefits') strategies. No-regrets solutions can contribute to disaster preparedness and climate resilience, while, at the same time, support sustainable livelihoods and socio-economic development. Examples include

$\circ$ Improved agricultural efficiency and income generation

- Added value of water utilization in general

- Improved drought resilience (including increased storage capacity, seed banks)

- Improved groundwater management and utilization

$\circ$ Improved drainage

$\circ \quad$ Education and awareness-building

- Intended improvements of existing livelihoods must be pursued with due caution, due to an ever-present risk of unforeseen adverse side effects. A gradual and stepwise approach must be preferred wherever the choice is open.

- Education (at all levels) and awareness-building are safe strategies. Social marketing may be applied to promote good practices in general and disaster preparedness in particular.

One particular challenge is the clear preference of the households to stay at home for as long as possible in the face of imminent disasters. For several reasons evacuation is a decision with potential far-reaching implications. A gradual and step-wise approach, including progressive preparedness and a gradual response (such as early evacuation of vulnerable household members) will reflect current practices and is best suited for adaptation.

\section{Conclusion}

Exposures and vulnerabilities are site-specific, while response options comprise both general and site-specific measures. All will evolve in the course of time, affected by flood protection measures, bank erosion, changed land use, infrastructural development, new cultivation systems, and climate change. 
The newly formed VDMCs appear as auspicious platforms for improved disaster resilience. Headed by the village chiefs, they capture the indispensable local knowledge about site-specific concerns and adaptation needs. On the other hand, they are not always aware of unfamiliar adaptation options, such as improved cultivation and livestock breeding or new (alternative or supplementary) livelihoods. Support is warranted.

\section{References}

[1] ADPC: Community-based disaster risk reduction. Asian Disaster Preparedness Center, Bangkok (August 2010).

[2] ASDMA: Assam State Disaster Management Plan. Assam State Disaster Management Authority (May 2013).

[3] ASDMA: Best Practice for Flood Early Warning System. Assam State Disaster Management Authority in collaboration with North Eastern Space Application Centre, India (May 2013).

[4] Bipul Talukdar and Mayuri Deka: Flash flood prediction. Proceedings of the Assam Water Conference 2014, 'Sustainable Development of Water Resources in the North-East Region', Guwahati, Assam, pp. 168-173 (February 2014).

[5] Das, Partha J.: Community-based flood early warning system implemented by Aaranyak and ICIMOD in the Lakhimpur and Dhemaji Districts of Assam: Learning and way forward. Slide presentation at the Assam Water Conference 2014, 'Sustainable Development of Water Resources in the North-East Region', Guwahati, Assam (February 2014).

[6] GoI and UNDP: Compendium on disaster risk management - booklet for legislators. Prepared by Government of India and United Nations Development Programme under the GoI-UNDP Disaster Risk Management Programme (in Hindi) (2007).

[7] GoI and UNDP: Good practices in community-based disaster risk management. Prepared by Government of India and United Nations Development Programme under the GoI-UNDP Disaster Risk Management Programme (2009).

[8] Guna Paudyal: Comprehensive approach to real time flood forecasting \& warning. Slide presentation at the Assam Water Conference 2014, 'Sustainable Development of Water Resources in the North-East Region', Guwahati, Assam. (February 2014).

[9] MHA: Disaster management in India. Ministry of Home Affairs, Government of India (March 2011).

[10] NDMA: Management of Floods. National Disaster Management Guidelines, National Disaster Management Authority, Government of India. (January 2008). 